\title{
The Magnitude of the Cancer Problem
}

\author{
By SIDNeY J. CUTLER, M.A., and William M. HAENSZEL, M.A.
}

\begin{abstract}
C ANCER is the second leading cause of death, ranking next to diseases of the heart. It now accounts for approximately 1 in every 7 deaths in the United States, with an annual toll of approximately 225,000 deaths.

Because of the lack of information from other sources, mortality data, in the past, have been relied on as a measure of the cancer problem. Important as they are, death statistics by themselves cannot define the problem adequately. Is therapy becomes increasingly effective, the more curable types of cancer will appear less frequently in mortality records. Furthermore, the medical certification of death cannot be viewed as a complete clinical history. In reporting the sequence of morbid events leading to death, the number of persons dying with cancer is inevitably understated. This can oc-

Mr. Cutler is an analytical statistician with the Biometry Section in the National Cancer Institute, National Institutes of Health, Public Health Service. Before joining the Public Health Service in November 1948, he was an analytical statistician with the Air Force School of Aviation Medicine (194748) and a senior statistician with the New York City Health Department (1946-47).

Mr. Haenszel is head of the Biometry Section of the National Cancer Institute. He was director of the bureau of vital statistics, Connecticut Department of Public Health, for 5 years and before that time a statistician with the New York State Department of Health, in Albany.
\end{abstract}

Vol. 69, No. 4, April 1954 cur because the certifying physician may not know or may neglect to indicate that cancer was present, or because death was obviously due to some cause unconnected with the presence of cancer.

\section{Estimates of Cases}

One method of obtaining data on the type and amount of illness in the population is the so-called household survey or family interview. This method is not suitable for cancer studies, and its failings may be attributed to the inability of the respondent to supply the correct information, because the physician may not have informed the family of the diagnosis, or because of the respondent's lack of familiarity with technical terms, or his unwillingness to discuss the subject with an interviewer.

The approach adopted by the National Cancer Institute of the Public Health Service has been to canvass all the diagnostic sources within a community-hospitals, clinics, laboratories, practicing physicians-and to obtain names of all persons coming to diagnosis or currently under treatment, so that an unduplicated count of persons ill with the disease might be made. Ten urban areas (Atlanta, Birmingham, Chicago, Dallas, Denver, Detroit, New Orleans, Philadelphia, Pittsburgh, and San Francisco) were surveyed by the Institute in 1937-39 and resurveyed in 1947 and 1948. To insure as complete coverage as possible, data on cancer deaths were obtained at the same time from city and State offices of vital statistics. The mor- 
tality records provided information on cancer cases not reported by other sources.

These cancer morbidity surveys have yielded a wealth of information for evaluating the size and nature of the cancer problem. Separate reports have been issued on each of the 10 areas (1), and a summary report is now being prepared. This paper contains a discussion of some of the broad implications of the findings of this series of 10 cancer surveys.

In the 10 cities resurveyed in 1947 and 1948, cancer was diagnosed at an annual rate of 319 new cases per 100,000 population; of every 100,000 persons, 430 were under treatment for the disease sometime during the year. Since the average age of the 10-city population is somewhat younger than for the country as a whole, rates for specific age categories were computed and applied to the age distribution of the United States population in 1950, for the purpose of making national estimates. The incidence rate (new cases per year per 100,000 population) for the United States is estimated - to be 328, and the prevalence rate (cases under treatment during the year per 100,000 population) is estimated to be 441 . The estimated rates may overstate the true rates for the total United States since current evidence suggests that rates are higher in urban than in rural areas. However, this may compensate for undiagnosed cases for which no allowance has been made.

The age-specific cancer illness rates can also be used for making forecasts. Estimates for the United States of the number of newly diagnosed cancer cases, cases under treatment, and deaths for 1940, 1950, and 1953, and forecasts of these numbers for future years, 1960-75, are presented in table 1 . The forecasts were made on the assumption that the prevailing agespecific rates will continue. In the 10-year period $1937-47$, the age-specific incidence rates increased an average of 14 percent. It is likely that further increases in the rate of cancer incidence will be observed during the next 2 decades, as a result of improved diagnostic and case-finding techniques or increased exposure to carcinogenic hazards. Thus, the projected figures may be considered to be minimal.

Even if the current age-specific incidence, prevalence, and mortality rates were to remain constant, the number of persons affected by cancer will increase by about 50 percent during the next 25 years. This is true for two reasons : The total population of the United States is expected to increase, and the proportion of persons in the older age groups is expected to increase (2). For example, in 1950, 8.2 percent of the population was 65 years of age or older; this proportion is expected to increase to 10.4 percent by 1975. Thus, we see that the expected population trend alone will greatly increase the magnitude of the cancer control problem in the United States, even if the rate of cancer incidence remains constant.

Table 1. Estimates ${ }^{1}$ of cancer incidence, prevalence, and mortality, United States, 1940-75

\begin{tabular}{|c|c|c|c|}
\hline Year & $\begin{array}{l}\text { New } \\
\text { cases }\end{array}$ & $\begin{array}{c}\text { Cases } \\
\text { under } \\
\text { treatment }\end{array}$ & $\begin{array}{l}\text { Cancer } \\
\text { deaths }\end{array}$ \\
\hline $\begin{array}{l}1940 \\
1950 \\
1953 \\
1960 \\
1965 \\
1970 \\
1975\end{array}$ & $\begin{array}{l}380,000 \\
497,000 \\
530,000 \\
605,000 \\
656,000 \\
706,000 \\
753,000\end{array}$ & $\begin{array}{r}528,000 \\
668,000 \\
711,000 \\
811,000 \\
879,000 \\
945,000 \\
1,008,000\end{array}$ & $\begin{array}{r}2165,255 \\
2210,733 \\
225,000 \\
259,000 \\
282,000 \\
304,000 \\
326,000\end{array}$ \\
\hline
\end{tabular}

1 Estimates are based on Census Bureau population projections-Current Population Reports (2), Series P-25, No. 78 (Aug. 21, 1953).

2 Actual number reported by the National Office of Vital Statistics, Public Health Service.

\section{Age Differences in Cancer Incidence}

The incidence of new cases of cancer increases very rapidly with increasing age. For example, the incidence rate is about 40 per 100,000 population at age 25,475 at age 50, and 1,900 at age 75. The changes in cancer incidence with respect to age are shown, as a curve, in the chart. There is only one reversal in the increasing rate with increasing age. This occurs at the very young ages. The incidence rate among children under 5 years of age is higher than in children 5 to 14 .

We are inclined to emphasize the increase in cancer illness at the older ages, and this is natural, because the rates at the older ages are high. However, when we think in terms of 
actual numbers of new cases, we must not overlook the very substantial number among children and young adults. For example, roughly 1 of 6 newly diagnosed cases was under 45 years of age. The chart illustrates the difference between the age distribution of newly diagnosed cases of cancer (shown as a series of columns) and the variation, with respect to age, of the rate at which cancer occurs (shown as a curve). After early childhood, the proportion of new cases in each 5-year age group increases to a peak at 60 to 65 and then decreases. The age at which the greatest number, or proportion, of cases occurs depends on the age distribution of the population from which the cancer cases are drawn. For example, if the population of the United States were older, the peak might occur at ages 65 to 70 , whereas if the population were younger, the peak might occur at ages 55 to 60 . The cancer incidence rate, however, continues to increase into very old age.

It is important to differentiate between the information provided by a percentage distribution of newly diagnosed cases and that provided by age-specific incidence rates. The age-specific cancer incidence rates provide a measure of the risk of developing cancer during a specified period of time (1 year, 5 years, and so forth) for persons of a given age or age group. They also serve as an index of the case-finding rate one may expect in different age groups in the population. The age distribution of newly diagnosed cases cannot be used as a measure of risk or rate of case finding, unless we know the age distribution of the population from which these cases came. Approximately 4 percent (3.8 percent) of persons with newly diagnosed cancer were 35-39 years of age. Another 4 percent (4.1 percent) were 80-84 years of age. However, the number of persons in the population who are 35-39 years of age is far greater than the number 80-84 years of age. (In 1950 in the United States, there were 11,246,000 persons $35-39$ years of age and $1,059,000$ persons 80-84 years of age.) Thus, when the number of diagnosed cases (approximately equal in the 2 age groups) is divided by the number of persons in each age group, the annual cancer incidence rate becomes 148 per 100,000 persons
Newly diagnosed cases of cancer, 10 urban areas, 1947-percenfage distribution and rate of incidence, by age.

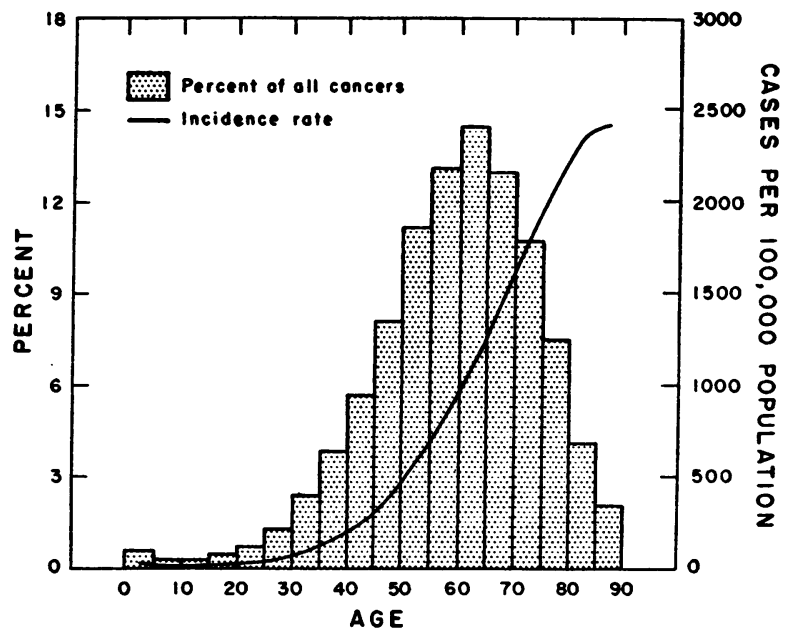

$35-39$ years of age compared to a rate of 2,372 per 100,000 persons 80-84 years of age.

Both types of information are important and useful. For example, in planning a large-scale cancer case-finding program, we would have to compromise between at least three conflicting goals in applying any specified technique: $(a)$ finding cases among relatively young people, in order to salvage the maximum number of productive years of life; $(b)$ producing a high proportion of positives in the screened population, to make the program economical; and $(c)$ finding as many cases as possible, in order to save the maximum number of lives.

Concentration on young people, let us say persons 30 to 50 years of age, would satisfy the first goal. However, the rate of cancer incidence is relatively low in this age group. Consequently, the proportion of cases found in the screened population would be low, and the number of cancers discovered would also be small. Concentration on old people, let us say persons 70 years of age and older, would produce a high proportion of positives since the cancer incidence rate is high among old persons. However, this approach ignores the desirability of salvaging productive years of life, and it would also produce a small number of cases since the number of old people in the population is relatively small. Concentration on persons 50 to 70 years of age would be fairly productive for two reasons: The rate of can- 
cer incidence among persons in this age bracket is sizable, and about half of all cancer cases diagnosed during any time period are found among persons in this age category. Thus, a relatively large number of cases would be found and the case-finding rate would be relatively high. The decision as to which age segments of the population to concentrate on would depend on the specific aims of the program.

\section{Probability of Developing Cancer}

In the analysis of data relating to cancer or certain other chronic diseases, the use of measures based on 1-year exposure to risk (annual rates) for incidence or mortality seems particularly inadequate. For most forms of cancer, long latent periods between exposure to carcinogenic agents and development of neoplasms are suspected. Consequently, cancer investigators need to follow population groups over long periods of time and tend to think in terms of the risk of developing the disease over intervals as long as 10 or 20 years. For many purposes, the size of study groups needed to yield significant results can be held at manageable proportions only by arrangement for prolonged observation or followup.

The scientific viewpoint coincides with popular interest. An individual is not too greatly interested in the probability of his developing cancer within the next year. He is more concerned with the chances of developing cancer between his present age and the close of his working career, age 65 or 75 , or at any future time during his life. Answers to when a person may be expected to develop cancer in the future may be found by resorting to conventional life table methods, and depend on the interplay of two forces-the schedule of age-specific cancer incidence rates and the risk of removal from the population by competitive causes of death.

The probabilities in table 2 , for selected intervals of the life span, are based on the cancer incidence rates of the 1947 survey and general mortality experience during 1950 (except for the set of 1940 figures presented for comparison). Under current conditions, 32 of every 100 newborn children may be expected to derelop cancer at some time during their life; cancer would develop in 3 persons before age 45 , and 14 and 23, respectively, are the corresponding figures for ages 65 and 75 . Examination of the table reveals the striking magnitude of the risks encountered in the portions of the life span after age 45 . The slightly higher probabilities at age 20 than for the corresponding figures at time of birth result from the comparatively high mortality during infancy from causes other than cancer.

Table 2. Percentage of persons expected to develop cancer during their future lifetimes, by age, 1940 and 1950 compared

\begin{tabular}{|c|c|c|c|c|}
\hline \multirow{2}{*}{1940 and 1950 comparisons } & \multicolumn{4}{|c|}{ Percentages beginning at- } \\
\hline & Birth & Age 20 & Age 45 & Age 65 \\
\hline $\begin{array}{l}\text { 1950: }{ }^{1} \\
\text { By age 20 } \\
\text { By age 45 } \\
\text { By age 65 } \\
\text { By age } 75 \\
\text { During future lifetime } \\
\text { 1940: }{ }^{2} \\
\text { During future lifetime }\end{array}$ & $\begin{array}{l}0.3 \\
3 \\
14 \\
23 \\
32 \\
23\end{array}$ & $\begin{array}{r}3 \\
15 \\
24 \\
33 \\
\\
25\end{array}$ & $\begin{array}{r}13 \\
23 \\
32 \\
25\end{array}$ & $\begin{array}{r}r 13 \\
26\end{array}$ \\
\hline
\end{tabular}

1 Based on 1947 incidence rates and 1950 life table.

2 Based on 1937 incidence rates and 1940 life table.

By applying the probabilities illustrated in table 2 to the current population of the United States, it is estimated that approximately 50 million people now alive will develop cancer during their remaining lifetimes.

The rise in the age-specific cancer incidence rates between the first and second surveys and the decline in the general mortality level between 1940 and 1950 were both responsible for the shift in the lifetime probability of developing cancer, from 0.23 in 1940 to 0.32 in 1950 . The 1937 incidence rates combined with the general mortality level prevailing in 1950 would have yielded a lifetime probability figure of 0.27. Thus, it seems clear that even if the present schedule of age-specific cancer incidence rates were to remain unchanged (as previously indicated, it is more likely that the age-specific rates will continue to increase), an upward trend in the lifetime probability of developing cancer would continue, by virtue of the progressive lowering of mortality from other causes.

Women are more likely to develop cancer sometime during their lives than men; white 
Table 3. Lifetime probabilities of developing cancer, age-adjusted cancer incidence rates, and average life expectancy, by color and sex

\begin{tabular}{|c|c|c|c|}
\hline Color and sex & $\begin{array}{c}\text { Lifetime } \\
\text { probability } \\
\text { of devel- } \\
\text { oping } \\
\text { cancer } \\
\text { (percent) }\end{array}$ & $\begin{array}{c}\text { Age- } \\
\text { adjusted } \\
\text { cancer } \\
\text { incidence } \\
\text { rates (per } \\
100,000 \\
\text { popula- } \\
\text { tion) }\end{array}$ & $\begin{array}{l}\text { Average } \\
\text { life } \\
\text { expect- } \\
\text { ancy } \\
\text { (in years) }\end{array}$ \\
\hline $\begin{array}{l}\text { White men } \\
\text { White women } \\
\text { Nonwhite men } \\
\text { Nonwhite women }\end{array}$ & $\begin{array}{l}31 \\
36 \\
17 \\
22\end{array}$ & $\begin{array}{l}338 \\
333 \\
253 \\
293\end{array}$ & $\begin{array}{l}66.6 \\
72.4 \\
59.2 \\
63.2\end{array}$ \\
\hline
\end{tabular}

Note: Based on 1947 cancer incidence rates in 10 urban areas and 1950 life tables for the United States.

persons are more likely to develop cancer than nonwhite persons (table 3). These differences are the result of the interplay of two factorsthe schedule of age-specific cancer incidence rates and the average number of years that persons in each color-sex group can expect to live. Of particular interest is the difference in the lifetime probabilities of developing cancer between male and female white persons. Although the cancer incidence rate for white men is slightly higher than for white women, 31 percent of newborn white male children are ex- pected to develop cancer during their lifetimes compared with 36 percent of newborn white female children. The difference is due primarily to the fact that white women can expect to live an average of 72.4 years, while white men can expect to live only 66.6 years.

The probabilities, for white men and women, of developing cancer in six selected site groups are given in table 4 . In men, the risk of developing cancer of the digestive system is dominant, with a lifetime probability at birth of 10.3 in 100. In women, the risk of developing cancer by age 65 is highest for the genital organs and breast sites. However, the risk of developing digestive cancer after age 65 increases so rapidly that digestive system outranks genital organs and breast as a cancer risk in overall lifetime probability. In both men and women, the probability of developing cancer of the digestive system from age 65 on is very substantial-9.9 per 100 men and 8.4 per 100 women aged 65 .

\section{Early Diagnosis}

Early diagnosis of cancer cases is generally recognized to offer the most hope for successful treatment. This principle of cancer control is supported by data collected through followup

Table 4. Percentage of white persons expected to develop cancer during their future lifetimes: six selected site groups by sex and age ${ }^{1}$

\begin{tabular}{|c|c|c|c|c|c|c|c|c|}
\hline \multirow{2}{*}{ Primary site group } & \multicolumn{4}{|c|}{ Men, beginning at- } & \multicolumn{4}{|c|}{ Women, beginning at- } \\
\hline & Birth & Age 20 & Age 45 & Age 65 & Birth & Age 20 & Age 45 & Age $6 j$ \\
\hline Digestive system: & & & & & & & & \\
\hline By age 65. & 4. 0 & 4. 1 & 4. 0 & & 3. 3 & 3. 4 & 3. 2 & \\
\hline During future lifetime & 10. 3 & 10. 8 & 11. 1 & 9. 9 & 9. 8 & 10. 2 & 10. 2 & 8. 4 \\
\hline Respiratory system: & 10 & 0 & 0 & & 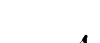 & & & \\
\hline $\begin{array}{l}\text { By age } 65 \\
\text { During future lifetime }\end{array}$ & $\begin{array}{l}1.9 \\
3.4\end{array}$ & $\begin{array}{l}2.0 \\
3.5\end{array}$ & $\begin{array}{l}2.0 \\
3.6\end{array}$ & $-\overrightarrow{2.3}$ & .4 & $\begin{array}{l}.4 \\
.9\end{array}$ & $\begin{array}{l}.4 \\
.9\end{array}$ & $-1-6$ \\
\hline $\begin{array}{l}\text { Breast: } \\
\text { By age 65 }\end{array}$ & & 1 & & & 4. 0 & 4. 1 & 3.3 & \\
\hline During future lifetime & -- & - n & 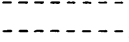 & 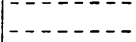 & 7. 5 & 7. 8 & 7. 1 & $4 . \overline{6}$ \\
\hline $\begin{array}{l}\text { Genital organs: } \\
\text { By age 65 }\end{array}$ & $\therefore 7$ & $\therefore 7$ & .6 & 51 & 4. 5 & 4. 7 & 3.8 & \\
\hline $\begin{array}{l}\text { During future lifetime } \\
\text { Urinary organs: }\end{array}$ & $\begin{array}{r}4.0 \\
.9\end{array}$ & 4. 2 & $\begin{array}{r}4.3 \\
9\end{array}$ & 5. 1 & 7. 2 & 7. 4 & 6. 6 & 3. 4 \\
\hline $\begin{array}{l}\text { During future lifetime } \\
\text { Skin: }\end{array}$ & 2. 3 & 2. 4 & 2.4 & $2 . \overline{2}$ & 1. 4 & 1. 5 & $\dot{1 .} \tilde{5}$ & 1. $\overline{3}$ \\
\hline $\begin{array}{l}\text { Skin: } \\
\text { By age } 65\end{array}$ & 2. 2 & 2. 3 & 2. 0 & & 1. 7 & 1. 8 & 1. 4 & \\
\hline During future lifetime & 5. 1 & 5. 3 & 5. 2 & 4.4 & 4. 6 & 4. 7 & 4.5 & 3. 7 \\
\hline
\end{tabular}

1 Based on 1947 incidence rates and 1950 United States life table. 
of cancer patients. Information on the survival experience of cancer patients with respect to the stage of development of the cancer at the time it was diagnosed is contained in table 5 . The data are drawn from the cancer register maintained since 1935 by the State of Connecticut (3) and from the cancer morbidity surveys conducted by the National Cancer Institute in 10 urban areas, in 1947-48 (1). Each series is based on the experience of more than 40,000 cancer patients.

Table 5. Number of survivors out of every 100 diagnosed cases of cancer, by stage af diagnosis

\begin{tabular}{|c|c|c|c|c|}
\hline \multirow{2}{*}{ Stage at diagnosis } & $\begin{array}{c}10 \text { urban } \\
\text { areas }^{1}\end{array}$ & \multicolumn{3}{|c|}{ Connecticut } \\
\hline & 1 year & 1 year & 5 years & $\begin{array}{c}10 \\
\text { years }\end{array}$ \\
\hline All cancers & 64 & 54 & 27 & 16 \\
\hline $\begin{array}{l}\text { Localized } \\
\text { Regional involvement } \\
\text { Remote metastases. }\end{array}$ & $\begin{array}{l}84 \\
58 \\
28\end{array}$ & $\begin{array}{l}72 \\
50 \\
14\end{array}$ & $\begin{array}{r}43 \\
20 \\
3\end{array}$ & $\begin{array}{r}26 \\
11 \\
1\end{array}$ \\
\hline
\end{tabular}

1 Surveyed by the National Cancer Institute, Public Health Service, in 1947-48.

Examination of table 5 indicates that the chances for survival of cancer cases diagnosed early (while localized at the site of origin) are much better than for cases diagnosed after the tumor has spread to adjacent tissues (regional involvement) or to other organs (remote metastases). For example, of every 100 persons diagnosed as having cancer while localized, 43 lived for at least 5 years after diagnosis, whereas of every 100 persons diagnosed as having cancer after other organs had been invaded only 3 survived 5 years.

In view of the evident benefits of early diagnosis, it is unfortunate that only half of all persons with cancer are being diagnosed while the disease is localized at the site of origin. This record could be improved materially, because half of all cancers develop in organs accessible to direct examination by the physician in his own office. Yet, only 62 percent of cancers developing in accessible sites are discovered in an early stage, and when skin cancers, which generally do not spread to other organs, are excluded, only 50 percent of accessible cancers are diagnosed early. The record of each accessible site with respect to the percentage of cases diagnosed while localized is shown in table 6. Noteworthy here is that in cancer of the breast-a highly accessible site-only 2 of every 5 cases are diagnosed while the cancer is localized. For cancer of the rectum, in both sexes, the proportion is less than half; for cancer of the prostate, one-half; and for cancer of the uterus, the proportion is less than 3 out of 5 .

Table 6. Cancer sites accessible to direct examination: percentage diagnosed while localized, by sex, 10 urban areas, $1947-48$

\begin{tabular}{|c|c|c|c|c|c|}
\hline \multicolumn{3}{|l|}{ Men } & \multicolumn{3}{|l|}{ Women } \\
\hline Primary site & $\begin{array}{c}\text { Percentage } \\
\text { of all } \\
\text { newly } \\
\text { diagnosed } \\
\text { cases }\end{array}$ & $\begin{array}{l}\text { Percentage } \\
\text { diagnosed } \\
\text { while } \\
\text { localized }\end{array}$ & Primary site & $\begin{array}{l}\text { Percentage } \\
\text { of all } \\
\text { newly } \\
\text { diagnosed } \\
\text { cases }\end{array}$ & $\begin{array}{l}\text { Percentage } \\
\text { diagnosed } \\
\text { while } \\
\text { localized }\end{array}$ \\
\hline $\begin{array}{l}\text { Skin } \\
\text { Prostate } \\
\text { Rectum } \\
\text { Mouth and pharynx }\end{array}$ & $\begin{array}{r}15.4 \\
9.5 \\
6.5 \\
6.3 \\
.3\end{array}$ & $\begin{array}{l}94 \\
50 \\
45 \\
61 \\
49\end{array}$ & $\begin{array}{l}\text { Breast } \\
\text { Uterus } \\
\text { Skin } \\
\text { Rectum } \\
\text { Mouth and pharynx } \\
\text { Thyroid... }\end{array}$ & $\begin{array}{r}21.7 \\
18.9 \\
10.7 \\
4.5 \\
2.0 \\
1.1\end{array}$ & $\begin{array}{l}40 \\
57 \\
95 \\
46 \\
74 \\
65\end{array}$ \\
\hline $\begin{array}{l}\text { Total accessible sites } \\
\text { Total accessible sites } \\
\text { (excluding skin) }\end{array}$ & $\begin{array}{l}38.0 \\
22.6\end{array}$ & $\begin{array}{l}70 \\
52\end{array}$ & $\begin{array}{l}\text { Total accessible sites } \\
\text { Total accessible site- } \\
\quad \text { (excluding skin) }\end{array}$ & $\begin{array}{l}58.9 \\
48.2\end{array}$ & $\begin{array}{l}58 \\
49\end{array}$ \\
\hline
\end{tabular}




\section{Summary}

The annual number of persons diagnosed with cancer is expected to increase from 530,000 in 1953 to 753,000 in 1975 . This estimated increase is based solely on two factors: the forecast increase in the number of persons in the United States, and the forecast increase in the proportion of older people in the population.

Though the figures on the annual number of new cancer cases are impressive, they do not provide an entirely satisfactory measure of the cancer problem. A more satisfactory measure is provided by estimating the probability of developing cancer by a specified age, or during a person's future lifetime. Application of the age-specific cancer incidence rates observed in 10 urban areas in 1947 to the 1950 life table revealed that roughly 50 million people alive in 1950 can expect to develop cancer during their remaining lifetimes, and that one-third of newborn children are expected to develop cancer during their lives. If cancer incidence rates and life expectancy continue to increase, as they have in the past, a substantially larger proportion of the population may be expected to develop cancer. These figures indicate that in terms of its impact on the population of the United States cancer is a major medical problem and promises to be a more serious problem in the future.

\section{REFERENCES}

(1) U. S. National Cancer Institute : Cancer illness in 10 urban areas of the United States, Cancer Morbidity Series, Reports 1-10, 1950-52. Washington, D. C., U. S. Government Printing Office, 1952.

(2) U. S. Bureau of the Census : Current Population Reports, Population Estimates, Series P-25, No. 78. Washington, D. C., The Bureau, 1953. Processed.

(3) Pollack, E. S.: Cancer survival picture brightens. Connecticut Health Bull. 67: 87-93 (1953).

\section{Nurses Conference on VD Control Concepts}

The University of Pennsylvania School of Nursing will conduct a work conference on current concepts of venereal disease control from May 24 to June 4, 1954, in Philadelphia. Designed for hospital and public health nursing supervisors, instructors in schools of nursing, consultants, and selected staff nurses from public health agencies, the conference has been organized chiefly to promote nursing education in venereal disease control.

The conference is sponsored by the School of Nursing and the Institute for the Study of Venereal Disease of the University of Pennsylrania in cooperation with the Pennsylvania State Department of Health, the Philadelphia Department of Public Health, and the Division of Special Health Services of the Public Health Service. Its planning committee and teaching staff include faculty members of the Schools of Medicine and Nursing and the departments of sociology and public health of the University of Pennsylvania, staff members of the Philadelphia Department of Public Health, and nurse consultants and physicians of the Public Health Service.

All applications for the conference will be reviewed by a committee on admissions. Requests for application forms should be addressed to Theresa I. Lynch, Dean, School of Nursing, University of Pennsylvania, 3400 Walnut Street, Philadelphia 4, Pa. 